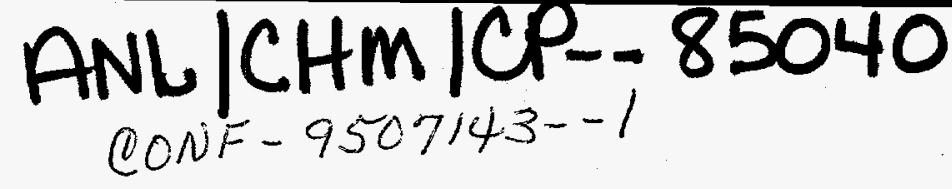

Invited Talk, for presentation at the 22nd Biennial Conference on Carbon, sponsored by the American Carbon Society, to be held in San Diego, CA on July 16-21, 1995.

\title{
DESIGNER CARBONS AS POTENTIAL ANODES FOR
}

\section{LITHIUM SECONDARY BATTERIES*}

R. E. Winans, K. A. Carrado, P. Thiyagarajan,**

G. Sandi, J. E. Hunt, and G. W. Zajac †ं

Chemistry and **IPNS Divisions Argonne National Laboratory

Argonne, IL 60439

$\dagger$ Amoco Research Center

Naperville, IL 60566
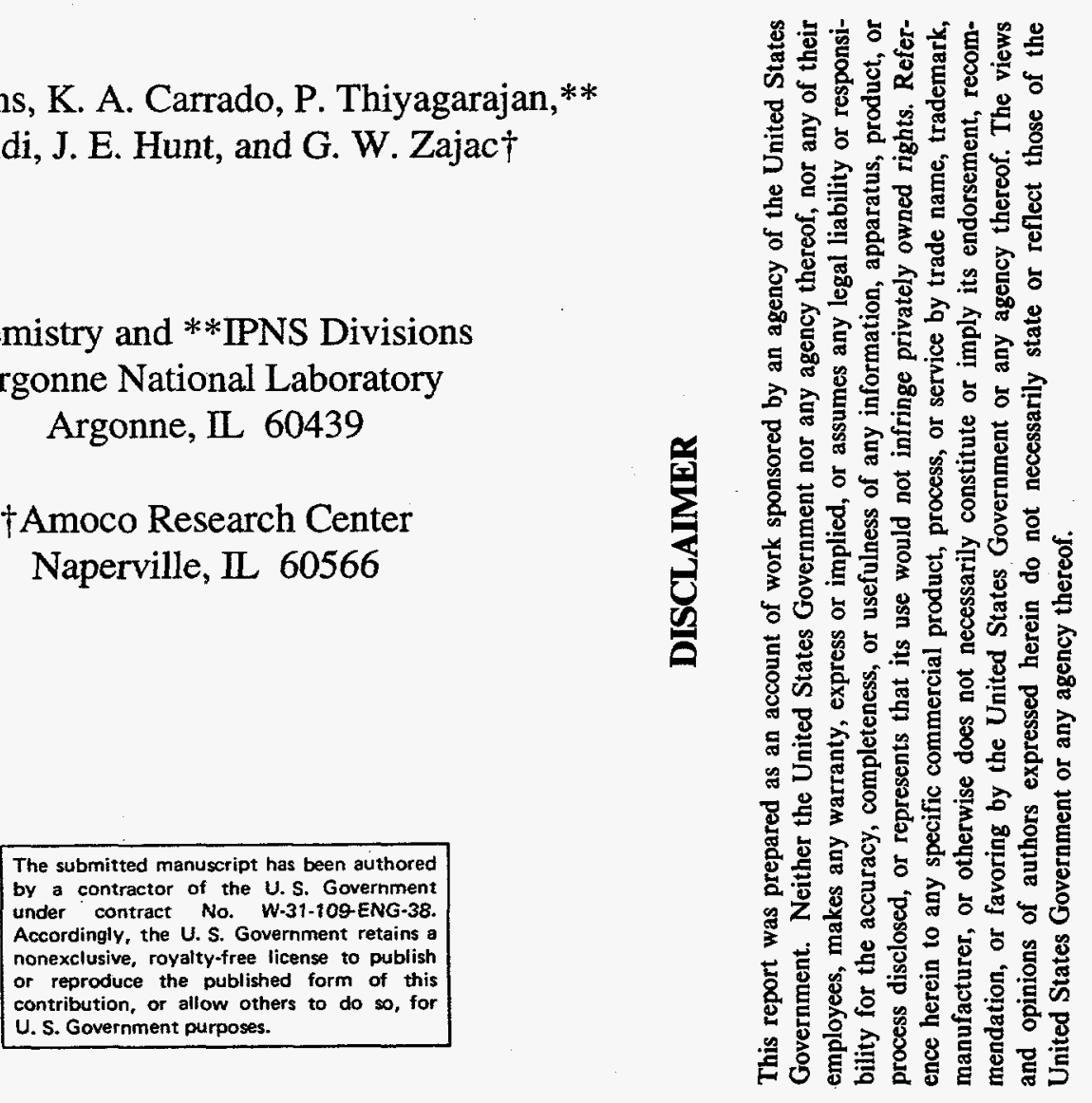

*This work was performed under the auspices of the Office of Basic Energy Sciences, Division of Chemical Sciences, U.S. Department of Energy, under contract number W-31-109-ENG-38. 


\section{DISCLAIMER}

Portions of this document may be illegible in electronic image products. Images are produced from the best available original document. 


\title{
DESIGNER CARBONS AS POTENTIAL ANODES FOR LITHIUM SECONDARY BATTERIES
}

\author{
R. E. Winans, K. A. Carrado, P. Thiyagarajan,* \\ G. Sandi, J. E. Hunt, and G. W. Zajact
}

Chemistry and *IPNS Divisions

Argonne National Laboratory

Argonne, IL 60439

\author{
$†$ Amoco Research Center \\ Naperville, IL 60566
}

\section{INTRODUCTION}

Carbons are the material of choice for lithium secondary battery anodes. Our objective is to use designed synthesis to produce a carbon with a predictable structure. The approach is to pyrolyze aromatic hydrocarbons within a pillared clay. Results from laser desorption mass spectrometry, scanning tunneling microscopy, X-ray diffraction, and small angle neutron scattering suggest that we have prepared disordered, porous sheets of carbon, free of heteroatoms [1].

One of the first demonstrations of template-directed carbon formation was reported by Tomita and co-workers, where polyacrylonitrile was carbonized at $700{ }^{\circ} \mathrm{C}$ yielding thin films with relatively low surface areas [2]. More recently, Schwarz has prepared composites using polyfurfuryl alcohol and pillared clays [3].

In the study reported here, aromatic hydrocarbons and polymers which do not contain heteroatoms are being investigated. The alumina pillars in the clay should act as acid sites to promote condensation similar to the Scholl reaction [4]. In addition, these precursors should readily undergo thermal polymerization, such as is observed in the carbonization of polycyclic aromatic hydrocarbons [5].

\section{EXPERIMENTAL}

The details of the preparation of the pillared clay from Bentolite $\mathrm{L}^{\circledR}$ and $\mathrm{Chlorhydrol}^{\circledR}$ have been reported [6]. The organics were loaded into the pillared clays by slurrying in a solvent and evaporation of the solvent or by thermal diffusion under vacuum conditions. The solvent loaded samples were heated in a sealed stainless steel tube at 700 ${ }^{\circ} \mathrm{C}$ for 4 hours. In the diffusion experiment, a 3-zone furnace was used and a tube sealed at one end as shown below:

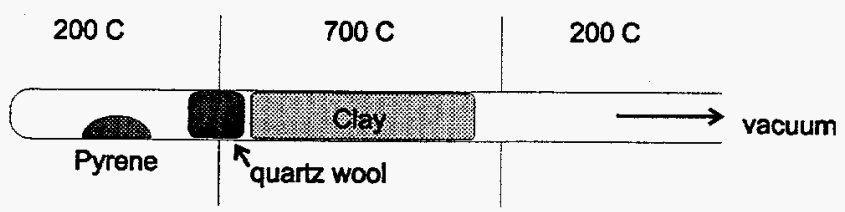

The aromatic hydrocarbon was distilled into the zone containing the clay at high temperature and simultaneously pyrolyzed. Typically, the experiment was run for 3 hours. The clay-carbon composition was demineralized by sequential treatments with cold $\mathrm{HF}$ and refluxing $\mathrm{HCl}$.

Characterization. X-ray powder diffraction (XRD) patterns of clay precursors and carbons were determined using a Scintag PAD-V instrument. Laser desorption mass spectroscopy (LDMS) was performed on a Kratos Maldi III. Small angle neutron scattering (SANS) experiments were done at the Intense Pulsed Neutron Source at ANL. The samples were placed in a small quartz cell with a path length of $1 \mathrm{~mm}$. Neutrons are produced in pulses by spallation due to the deposition of $450 \mathrm{MeV}$ protons on a depleted uranium target, followed by a solid methane moderator $(22 \mathrm{~K})$ yielding a wavelength range of 1 to $14 \AA$. Detection of scattered neutrons was accomplished with a $128 \times 128$ array, $40 \times 40 \mathrm{~cm}^{2}$ sensitive area, gas-filled proportional counter, and the wavelength of the scattered neutrons was determined by their times-of-flight. Data were corrected for unit transmission of the sample, the scattering cell and incoherent scattering. The accessible $q$ range ( $q=4 \pi \sin (\theta) / \lambda$ where $\lambda$ is the wavelength of the probing neutrons and $\theta$ is half the scattering angle) is from 0.008 to $0.2 \AA^{-1}$. Scanning tunneling microscopy studies were done at Amoco using a Digital Instruments Nanoscope II.

\section{RESULTS AND DISCUSSION}

An in-depth characterization study has been done on the carbon produced from a pyrene/clay complex formed by the solvent method. X-ray diffraction results suggest that the desired [7] highly disordered carbon has been formed with $d_{002}=3.44 \AA$. The surface area of this carbon is $23 \mathrm{~m}^{2} / \mathrm{g}$ which is the range demonstrated to be appropriate for lithium battery electrodes.

LDMS spectra suggest that this material is highly carbonized. Ions are observed to $>2500 \mathrm{amu}$. At low mass, small carbon clusters are seen: $C_{n}, n=4-20$, with a maximum at $C_{11}$. In addition, a less abundant series of $C_{n} H$, $\mathrm{n}=5,7,9$ is observed, but no peaks are seen for $\mathrm{C}_{n} \mathrm{O}$ or 
$\mathrm{C}_{\mathrm{n}} \mathrm{OH}$. These data suggest that oxygen is not taken up from the clay minerals.

Low resolution STM of the pyrene-PILC carbon shows "pillow" shaped structures on the order of 0.1-0.3 $\mu \mathrm{m}$. These are similar in size and shape to the original clay particles. At higher resolution, what appears to be steps in the basal planes of around $5 \mathrm{~nm}$ are observed. Finally, at the highest resolution, size fluctuations, which are interpreted as holes, are seen on the basal plane region and range in size from $15-50 \AA$.

SANS provides morphological information over a broad range of sizes (10-1000 $\AA$ ). The scattering intensity, $\mathrm{I}(\mathrm{q})$, as a function of scattering vector $(q)$ for the carbon is shown in Figure 1. In the low $q$ region, a power law slope of -2.8 indicates the extent of porosity present in the aggregated "pillow" shaped particles seen by STM. The distribution of packing imperfections (disorder which accounts for the large amount of porosity) leads to the mass fractal scattering behavior [8]. At an intermediate $q$ region, a power law slope of -2.0 is observed which indicates the presence of very large layered carbon sheets whose thickness is about $14 \pm 2 \AA$. The smallest size features are found in the highest $q$ region. After correcting the data for incoherent scattering, a maximum entropy technique [9] is used to analyze the high- $q$ data and the result is shown in Figure 2. This suggests that the carbon layers contain $15 \AA$ holes which is approximately the size expected from the $\mathrm{Al}_{13}$ pillars.

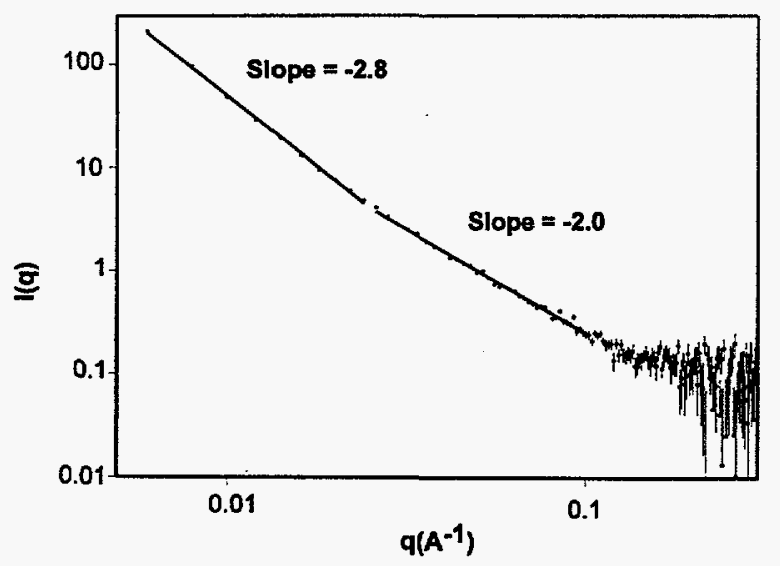

Figure 1. SANS of Carbon from Pyrene-PILC.

\section{CONCLUSIONS}

This designed carbon synthesis, which can be more easily controlled than traditional empirical procedures, is yielding materials with unique properties. The successful and more desirable low-temperature carbonization is based on the Scholl reaction, which is an acid-catalyzed condensation of aromatic hydrocarbons.

\section{ACKNOWLEDGMENTS}

This work was performed under the auspices of the Office of Basic Energy Sciences, Division of Chemical Sciences, U.S. Department of Energy, under contract number W-31109-ENG-38.

\section{REFERENCES}

1. R. E. Winans and K. A. Carrado, J. Power Sources 54, 11 (1995).

2. T. Kyotani, N. Sonobe, and A. Tomita, Nature $\underline{331}$, 331 (1988).

3. T. J. Bandosz, J. Jagiello, K. A. G. Amankwah, and J. A. Schwarz, Clay Minerals 27, 435 (1992).

4. R. Scholl, C. Seer, and R. Weitzenböck, Ber. 43, 2202 (1910).

5. I. C. Lewis, Carbon 18, 191 (1980).

6. K. A. Carrado, S. L. Suib, N. D. Skoularikis, and R. W. Coughlin, Inorg. Chem. 25, 4217 (1986).

7. J. R. Dahn, A. K. Sleigh, H. Shi, J. N. Reimers, Q. Zhong, and B. M. Way, Electrochim. Acta 38, 1179 (1993).

8. G. D. Cody, P. Thiyagarajan, R. E. Botto, J. E. Hunt, and R. E. Winans, Energy Fuels 8, 1370 (1994).

9. P. Thiyagarajan, J. E. Hunt, R. E. Winans, K. B. Anderson, and J. T. Miller, Energy Fuels (submitted).

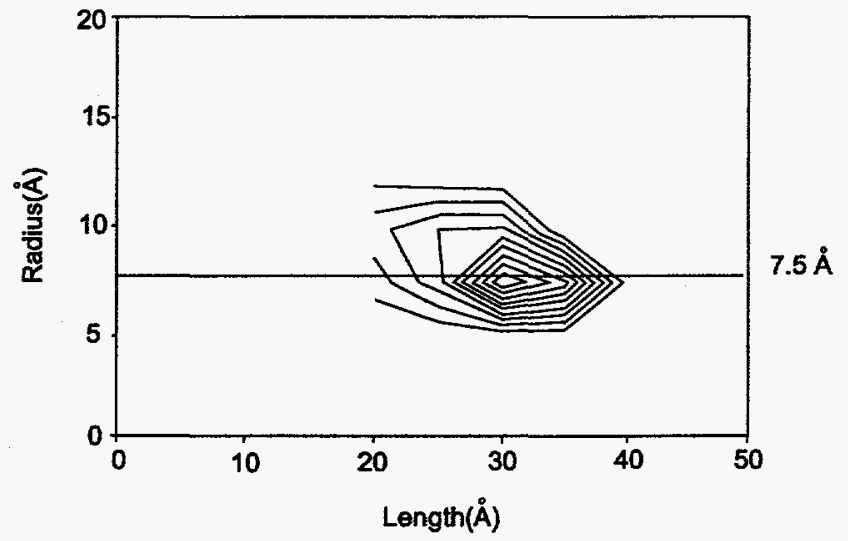

Figure 2. Maximum Entropy Analysis of SANS Data. 